\title{
ASSOCIATION OF PATIENTS' ORGANISATIONS IN THE FEDERATION OF BOSNIA AND HERZEGOVINA: SOCIAL PARTICIPATION CONCEPT
}

Azur Pašić, Maida Mulić- Šećerbegović, Ahmed Novo

(C) by Acta Medica Saliniana ISSN 0350-364X

Type of manuscript: Professional papers

\section{Title:}

ASSOCIATION OF PATIENTS ORGANISATIONS IN THE FEDERATION OF BOSNIA AND HERZEGOVINA: SOCIAL PARTICIPATION CONCEPT

\section{Authors:}

Azur Pašić

Maida Mulić- Šećerbegović ${ }^{2}$ Ahmed Novo ${ }^{1}$

DOI: $10.5457 / 481$

\begin{abstract}
Afiliations:
${ }^{1}$ Agency for Quality and Accreditation in Healthcare in the Federation of Bosnia and Herzegovina (AKAZ) ${ }^{2}$ Public Health Fund, Tuzla Canton and Medical Faculty University of Tuzla
\end{abstract}

Received:

11.01.2019.

\section{Corresponding author:}

Azur Pašić

Agency for Quality and Accreditation

in Healthcare in the Federation of

Bosnia and Herzegovina (AKAZ)

Email: pasic@akaz.ba

Tel: +38735303408

Mob + 38761280806

The civil sector should identify an appropriate form of representation through which the interests of all categories of patients will be expressed. The easiest way to achieve this goal is through Supreme Patient Association consisted of representatives from registered associations whose legally confirmed purpose is the exercise of patients' rights. The Association mission must be the policy of protecting the rights of all patients and patients' groups, while fulfillment of the obligation to protect the rights of the patients and the monitoring of the implementation of the Act would be its primary responsibility. The Initiative Committee should make an effort to gather representatives of existing patients' associations and other stakeholders, and guide them to form the umbrella association. At the same time, there needs to be made a clear distinction in terms of difference in respect to roles of the future founder. In short, the tasks of this association can be divided into three areas: raising awareness; encouraging authorities to respect the principles of equal protection of patients' rights; and collecting data on the state of patient rights protection. In conclusion, it logically seems completely clear and justified: 1. existence of one supreme/ umbrella association, 2. collection of relevant data in a methodologically correct manner by authorized bodies and from the entire territory for which the umbrella association was established; and 3. to inform the base on conclusions of analysies concernig particular issues - both for a specific location and for the entire territory (either the municipality; the canton; the federation).

Key words: Person centredness, Patient Rights, Patient Associations, Evidence Based Advocacy, AKAZ.

\section{INTRODUCTION}

Well established modern societies have a historical heritage of health and social protection that represent the civilization reach of unquestionable value and justification. From the moment of understanding that a person is the main single value for the whole society, this principle has procreated an effort to get adequate and permanent protection to this value. Therefore, every person in modern society exercises the right to protection as a patient, and this protection follows the individual from his/hers conception to natural disappearance, ie, death. The optimal exercise of the rights of patients' protection is achieved through bringing together both public and civil sector in the form of a partnership. In doing so, the civil sector needs to offer the appropriate form of representation through which the interests of all categories of patients will be equally represented. The easiest way to realize this prerequisit is through forming supreme / umbrella patients' association consisted of representatives from registered associations whose legally confirmed purpose is the exercise of patients' rights. Moreover, this partnership can be furtherly deepened by ensuring the participation of representatives of the umbrella association in the management boards of all public health institutions. It is necessary to use democratic methods of selecting delegates and securing principles that are considered a standard of democratic practice. The said participation refers to decision-making (strategies, policies, implementation decisions, etc.) that address all issues of patient rights protection in the form of using and prioritizing financial, material and human resources.

In order to provide competence in decision making and adequate representation of the interests of the electoral base, the patient representative is educated and advised, legitimized and delegated from authorized and responsible persons and structures. This represents a "New Paradigm" of the health care concept the one of partnership between the public and the civil sector.

The historical concept, according to which the state, as a result of the social contract, takes care of the health status of the nation in the general and on the individual level, implies perception of the civil sector as a 
supplemental. Namely, citizens' organizations receive a secondary role and a position of corrective that, depending on the lobbying success of a particular idea and / or project, is implemented through, and again, the state apparatus.

A systemic shift - according to which the civil sector has the role of a complement, represents a new model and, at the same time - a contemporary need that has to start with changed awareness. Thus, the perception of the problem of health care becomes a common domain of the public and civil sector in which each component gives its contribution and the contents for which it is predisposed and which combine to, overall, improved result.

This assumption requires readiness to cooperate and adoption of ideas and the facts that each side has a real need for the other. Moreover, this assumption also requires readiness to change, and and deviation from the narrow vision of one's own role. In practical terms, the civil sector turns towards achieving a higher degree of coordination between individual parts of its own corpus in order to be able to enter into the presumed partnership relationship completely legitimized

The civil sector represents a wealth of individual and / or group initiatives that do not have a competent control and organizational mechanism that would ensure uniformity and avoid the possibility of overlap, redundancy and competition. Each individual association runs a policy aimed at solving its own problem. This "tunnel vision" is completely justified from the perspective of the purpose of registering each of these associations, but, as a partner to a state where the intent is holistic and where it is assumed a continuous effort in the field of patient rights protection - it represents an unsurmontable obstacle and, necessarily - disqualifies those and such associations.

As for the state, that is, the public sector, on the other hand, in this cooperation formula, and the organizations of all its institutions - these are the structures that have historically passed the entire process of refining and operationalization. Thus, the state, that is, the public sector, has all prerogatives for the successful conduct of affairs for which it is authorized and for what purpose it is intended. While the civil sector's awareness of the need to cooperate with public sector is not in question, the same awareness is lacking in public sector.

The state is well equipped to work independently and to respond to its citizens for their own results through purely political mechanism - the elections. Thus this partnership is not "natural state" of the public sector but, much more - the necessity of consent to pressure.

\section{METHODS}

Regular communication with the civil sector is increasingly becoming not only a reality but also understanding of the opportunities to improve its own results and raising the degree of certainty of political success. Frequency of relations with representatives of the civil sector strengthens awareness of the benefits of such a relationship. Provided condition of respect for legality and the principles underlying the operation of the public sector in the case and the civil sector as well - namely: legitimacy, systemicity, purposefulness, equality, etc., the civil sector can easily grow into a fullsize partner with a clear mandate complementary to state institutions.

The need for systematicinclusion of the civil sector needs to be strengthened by clear lines of communication and provison of reliable relation of responsibility. The very intention of protecting the rights of (all) patients demands the need of a legitimate representative, that is, a sound process of election of a representative who will simultaneously conduct a policy of protecting all patients.

In order to achieve this, it is also necessary to provide a critical mass of individual associations that provided the respect of relevant democratic principles and solutions would result in the election of a representative and a mandate that does not come into question.

In this way, we come to the formation of an umbrella association of patients that in its scope has only that type of activity that applies to all patients, without discrimination, and without favoritism.

The problem that is understandable, which lies in the fact that the state can not successfully form a partnership if, as a potential partner - from the other side, there is some patient association, or always some different association of patients, is possible to overcome only if it is ensured that there is only one Partner; and always the Same. The need of existence of such the Partner with whom to have communication equality, efficiency and continuity, will be fulfilled by establishment of the umbrella association thus to have a single interlocutor and associate in joint activities.

The mission of Supreme /Umbrella Patient Association must be the policy of protecting the rights of all patients and patients' groups, while its primary responsibility would be fulfillment of the obligation to protect the rights of the patients and the monitoring of the implementation of the Law. Although the state, by definition, is the implementing actor of positive regulations and has mechanisms for checking and monitoring the situation and changes in the domain of given content and scope, rights and powers, those rights and powers are always best perceived by - the beneficiary. Also in the field of patients' rights there is an inherent need for effective involvement of patients in the function of monitoring in terms of their rights, and protection of their righs. Furthermore, the Association should persue the ensuring of the fulfillment of the principle of equal access to healthcare and use of the right to health care for all patients throughout the territory by encouraging the holders of responsibility to comprehensively execute their mandates.

Some other important aspects of the Association's activities are as follows: participation in health councils at all levels of government and participation in decision- 
making by participating in the Governing Boards of public health institutions; monitoring the waiting lists and essential lists; gathering relevant information and statistics, and cross-cutting existing databases; stimulating and encouraging the development of a unified patient database; and periodical reporting to its members and the public about the rights of patients.

Considering the issue of the principles that form the basis for conception and work of the umbrella association of patients, it is possible to set up a very extensive network. This is thanks to the fact that the patient category is one of the broadest categories in general. Virtually every person who is born, lives and dies in the territory of any civilized community around the world, at some point in their existence becomes - a patient, or is at least included in the health care system. Therefore, it is ontologically correct to assert that the principles that are pertinent to the notion "patient", and "patients'rights", are the same as the principles pertinent to notions of "mankind", and "human rights".

The principles pertaining to the existence of this association must correspond with the principles pertaining to the health care as provided in the Law on Health Care: accessibility, fairness, comprehensiveness, continuity, specialized approach, continous improvement of health care quality, security and efficiency. In particular, the principle of participation and the principle of social relevance and equity must not be forgotten by any means.

\section{RESULTS}

This section includes the results of our research on current legislation, the role of the Agency for Quality and Accreditation in Healthcare in the Federation of Bosnia and Herzegovina (AKAZ), the partnerships of the public and non-government sector, i.e. data on the state of patient rights protection.

The Law i.e. regulations regarding the establishment of the association of citizens represent the legal basis and provide a framework for determining both the purpose and the way of work, and all other issues relevant to this problem, so that in this modern society organized universe, indeed - there is no ambiguity. However, when it comes to a specific association that is an umbrella, which has the character of association of associations, then it is advisable to provide certain credibility, or legitimacy to the future structure as a representative of all those associations that recognize it.

Namely, an association that, according to the Law, can be founded by only three citizens, it would not, of course, be unlawful, but in this particular case, it would be lacking in recognition for - representative - by all similar (patient associations). It is therefore necessary to carry out the establishment of umbrella association in several steps, i.e. phases, in order to provide information to existing patient associations about the purpose of such an umbrella association, and to invite their representatives to participate in the establishment. In this way, the Initiative Committee would take these initial steps and function as the starting point of the interest in the association until the moment of the official take-over of the relevant functions of for that purposes responsible authorities and / or individuals. This first step towards joining of associations is very important because the awareness of the importance, tasks and possibilities of the future structure can exist only within the group of individuals and / or organizations that are not already involved in a specific association and have no obligation to belong to a particular policy and strategy. On the other hand, this founding group should have a clear view of its own role as temporal and revoking.

By fulfilling the initial purpose - ends the need for the existence of such an informal creation and thus, the Initiative Committee ceses to exist. This means that the Initiative Committee should make the effort to bring together representatives of existing associations and, possibly, other interested parties, as well as to direct them to establishing of the umbrella association, but at the same time it needs to distance itself from the role of founder. At the same time, this does not mean that those involved in these activities can not, as independent and unbiased individuals, be included in the final product of their own activities, but these two roles are essentially and functionally - different.

To the question about who can start the establishment of the umbrella association, as it was written earlier - the answer is contained in positive regulations. Furthermore, it is clear that there are no specific limitations that would exclude any legal and / or physical person from the circle of potential founders of the association of citizens. However, to the question of who is interested in founding an assosication, in this case - association of patients, the answer goes beyond to theoretical and not practical sphere. By formulating the question in exactly this way, it is possible to explore the character of the founder.

Taking into account the previous explanation of the so-called "Partnership formula" between the public and the civil sector, we get a clearer picture. So, any interest group and / or individual dealing with issues related to health, as a one-time, sporadicaly and / or systematicaly, from both circles - the public and civil, can be founders provided they have a clear vision and quality solution to problem of protecting the rights of patients and putting the patient in the focus and center of health and health care.

This explanation is also a guide to seeing AKAZ as a legitimate and competent factor that has interest, expertise and the possibility to initiate the establishment of the umbrella patient association. AKAZ in its job description has no any explicitly stated activity regarding the establishment of this or any similar association. However, when we analyze its mandate, mission and vision, it is clear that AKAZ is fairly invited to be the initiator of this and such an association.

When representatives of the civil sector are provided to also be members of the Initiative Committee, a very 
strong and reliable framework for ensuring a critical mass of the patients' right holders is in place and from that point on it could and should grow up to the level of reliable party to resolve all and any matters concerning the management of resources dedicated to health care.

In order to fulfill a full response to the "partnership formula", ideally, Initiative Committee should have members from public sector from the Federal Ministry of health, Federal Health Care Institute, Federal Institute for Public Health and Agency for Quality and Accreditation; on the other hand, from the civil sector, it would be best to have representatives of the Red Cross; and those associations that have capillary presence in all (or at least in the majority) of cantons, and to ensure that the prospect of legitimacy from the initial activities is optimally satisfied.

Descending on the relevance scale, the composition of the Inititative Committee in which the representatives for any of the listed institutions and associations are present, will have greater credibility if they are closer to the said composition. The minimum that can be achieved in terms of the membership of the Initiative committee, which can be considered to satisfy this principle, would be to meet the requirement that the committee has representatives of both the public and the civil sector from at least three such organizations.

Collecting data regarding the state of patients' rights protection is a task that needs to be understood at several levels: Methodological; local vs. central; and cross- referencing databases.

The first issue with regard to the collection and management of data relates to the methodological approach and satisfying statistical rules and regulations that are crucial if one wants to have relevant and noteworthy indicators. If the umbrella association wants to have the credibility and influence when negotiationg with the bearers of obligations and responsibilities, then it must provide a set of data that is not questionable - either from the position of the methodology or in relation to the entities that are collecting data i.e. sorce and origine. By putting things like this, it is clear that the umbrella association should not be transformed into a statistical organization that carries out research lege artis and to wich this activity represent its purpose of existence. On the contrary, the data that the umbrella association should provide should be derived from those organizations that are authorized and verified for these jobs. The umbrella association should (only) send a precisely outlined request and send it to the responsible organization / body / institution that can competently respond to the said request.

Accordingly, the umbrella association must have a clear idea of which data, and what information indicates the status of patients' rights (but also other relevant phenomena that indicate, and provide unambiguous conclusions about the patients' rights). Furthermore,, the knowledge of to which institution to send a request for those data and information. Thus, the database provided in this way would not be questionable. At the same time, it even more clearly describes the way in which data is used, or, in general, the use of data by the umbrella association. Therefore, the umbrella association has a very specific task and obligation, namely: to use the data in a purposeful manner; and a way that will enable efficient and effective stimulation and encouragement of actors to improve their own work and performance.

The picture of the state of the protection of patients' rights on the territory (of $\mathrm{FBIH}$ ), which is related to the constitutional solutions for health care in $\mathrm{FBiH}$, can vary significantly from place to place; from the canton - to the canton; but also within the same territorial and administrative units - from the institution - to the institution. This aspect is very interesting when it comes to the protection of patients' rights in general. Namely, the possible deviations in this regard can be so significant and divergent that it is not possible to bring any decent conclusion and assessment from the neither local nor central level.

Suppose that in certain cantons the rights of certain groups of patients are not respected in a legally prescribed manner, while those same rights, in another canton, are fully respected; the conclusion about this specific right can never be correct in terms of the situation - at the level of Federation of $\mathrm{BiH}$. This example clearly indicates that only a specific, central umbrella association can be able to provide the relevant data capillarily collected and give a true and correct answer to any question concerning the whole territory (in our case - FBIH).

\section{DISCUSSION}

The umbrella association is, and it should be the supreme structure of the existing patients' associations. Also, the Association should be used as a resource center by all those who see themselves and / or the structures in which they are members, as the natural base of this structure. It is important to emphasize that the role of the umbrella association must not, and can not be seen as, in any way - privileged, superior, higher, etc. from any other patient association, in spite of the fact that centralized structures are ussualy considered both systemically and organically just - such (privileged, superior, higher). While such an observation is perfectly normal for the public sector and the practice of public institutions, In the case of the civil sector it is by no means a rule rather an exception.

So, the right way to perceive this umbrella association is to consider it as a certain form of service to the base from which it is derived. From there, the logically formed network of tasks that it needs to perform becomes obvious. In short, the tasks of this association can be divided into three domains: raising awareness, encouraging health authorities to respect the principles of equal protection of patients' rights and collecting data regarding the state of the rights of patients.

Task 1 - Raising awareness - it refers to strengthening the correct knowledge abot the patient as a person; his/ 
her rights and obligations; and participation in decisionmaking on all issues related to healthcare (through appropriate education). This task is the first and primary task of the umbrella association. A set of results depends on the good execution of this task, which than can make a significant shift not only regarding patients' rights but the healthcare as a whole too.

What is considered to be strengthening of the correct knowledge about the patient as a person and issues related to patient participation in the health decisionmaking process? The simplest answer is: systemic awareness-raising throughout society about the importance of adopting a "new paradigm", according to whcih every citizen accepts his/her role of patient and raises it to the level of personal obligation to put his/ her own set of skills and knowledge in the function of general health improvement

Therefore, the education that is carried out generaly, both on civic level as well as in the context of individual existing patient associations, needs to be directed towards the correct perception of the patient as a central figure of the overall health care. The patient perceived like that is NOT, however to be seen as an object of healthcare but rather as a subject, and an active promoter of healthcare improvements. This task must be clearly defined, elaborated and described in detail so that it does not go beyond the functional framework and material possibilities of the association. At the same time, it must be precisely directed towards the existing structures that are enabled to concretely perform specific tasks from this sphere.

In other words, the umbrella association is not supposed to perform these tasks by itself, but rather to find the best means and professionally qualified organizations and / or personnel that can do so. For example, education on quality and safety in healthcare, which is the essence of respecting the rights of patients, can be performed by AKAZ thus to provide for the highest level of training that can give guidance to groups of patients and / or representatives of the patients' association in a customized manner on how to participate in the right way in decision making process concerning this area.

Furthermore, the idea of linking with the educational institutions is very plausible, as well as lobbying to incorporate individual program solutions into existing curricula that would be facultative and that would be the basis of the subsequent dissemination of knowledge and training of patients for qualified and professional participation.

Finally, the Law stipulates the obligation of health council establishment at and within all levels of government, which is direct call to the umbrella association for the establishment of permanent links and continuing education of members of these Boards.

After establishing the correct perception on the notion of "patient", the second part of Task 1, within the logical unity of awareness raising, sets in motion, the one that concerns the protection of patients' rights. Thus, when the concept of a patient as a subject of health care is correctly adopted, there is a need for a clear vision of the protection of patients' rights - not as an imaginary and alienated obligation of the state and / or bearers of individual obligations, but rather as a common need and social interest for whose fulfillment all available resources need to be mobilized from both public and civil sector. This approach completes the "new paradigm" and materializes the understanding and acceptance of it, and strengthens the partnership where each side of this relation uses of the other for faster and easier fulfillment of one's own obligation. This approach completes the "new paradigm" and materializes the understanding and acceptance of it, and strengthens the partnership where each side of this relation uses of the other for faster and easier fulfillment of one's own obligation.

Task 2 relates to encouraging healthcare authorities to respect the principle of equal protection of patients' rights, and regular monitoring of the status of patients' rights and provides insight and corrective influence on government authorities and bearers of obligations.

Positive Regulations - The laws and by-laws applied in the Federation of $\mathrm{BiH}$ clearly define the bodies and bearers of the obligations that, within their work tasks, are obliged to implement the laws and to ensure the fulfillment of the principles whic, inter alia, provide for the protection of patients' rights. However, in their regular work, these subjects may be in a position to, systematically and / or randomly, deny and / or reduce respect for the principle of equal protection of patients' rights to a certain number of individuals. If such a defect grows into a phenomenon that becomes a contextual difference and which, however, is factually established, there is a need for reaction and correction of procedures in practice.

Of course, the relevant legal texts contain mechanisms that ensure that the bearers of obligations and responsibilities themselves follow their own performance and effects. However, sometimes this self-inspection and audit activity is insufficient, and it opens space for interventions of other participants in the process, that is, in this case - the patients.

Patients' associations established with a purpose to take care, of problems related to a particular disease and / or health condition of their own members and members of that specific community is not structurally posed and oriented towards the systemic protection of all patients. That is why it is necessary to have an umbrella organization in order to deal with this activity systemically.

Task 3 - concerns the collection of data on the state of patient rights protection. The monitoring of the state of patients'rights protection requires the possesing of relevant, significant and methodologically correctly collected data. This task that the Association needs to undertake is directly related to the previously described one and represents the prerequisite for the quality and substential monitoring of the state of the patients'rights protection and respecting of the equity principle. 
The sequence of the presentation of individual tasks of the umbrella association can be summarized led by the chronological character of the events in the context of the consideration of the protection of the rights of patients, but this is also possible based on the maiore ad minus principle in observingthe aspect of priorities, as well as the position of the intrinsic importance of each individual task. Bearing in mind that the elaboration of individual tasks, the description of jobs and outlining of working units of the future association represent the status questions that are to be answered by the future Founding Committee - the consideration of these issues which we treat in this section is more of the toretical nature. It is leyed out as the background issue and in relation to the starting point - the "new paradigm". It is also in function to integral understanding of the partnership that was explained; the need to establish an umbrella organization; and its positioning on a global map of health care actors dealing with health care issues and health protection in general.

In conclusion, it seems logically justified and completely clear: 1. to aim for a single supreme / umbrella patientes' association that is put in place, 2 . that such an association undertake the task to collect data in a methodologically correct manner provided by the authorized bodies; that the data pertains tothe whole territory for which the umbrella association was established; 3. to have such an association regularly do apposite analysis that is of the interest for its members and draws conclusions about each particular issue concerning patients' rights and protection of patients'rights - both for a specific location (be it municipality or canton), as well as for the entire federation; 4 . to do the monitoring through health councils; and 5 . to inform the public and members on the state of affairs regarding patients' rights and the protection of patients' rights.

\section{REFERENCES}

1. Law on Health Care. Official Gazette Federation of BiH no:. $46 / 10$.

2. AKAZ - Culture of Quality. Available at http://www.akaz.ba/ udoc/AKAZ_KK_Final_web.pdf on September 15th 2018.

3. Law on Associations and Foundations. Official Gazette Federation of $\mathrm{BiH}$ no.: 45/02.
4. Agency for Quality and Accreditation in Healthcare in Federation of Bosnia and Herzegovina. Available at http:// www.akaz.ba/agencija-parent on October 4th 2018.

5. Law on Rights, Obligations and Responsibilities of Patients. Official Gazette Federation of BiH no: 40/10. 